International Journal of

Health, Medicine and

Nursing Practice

(IJHMNP)

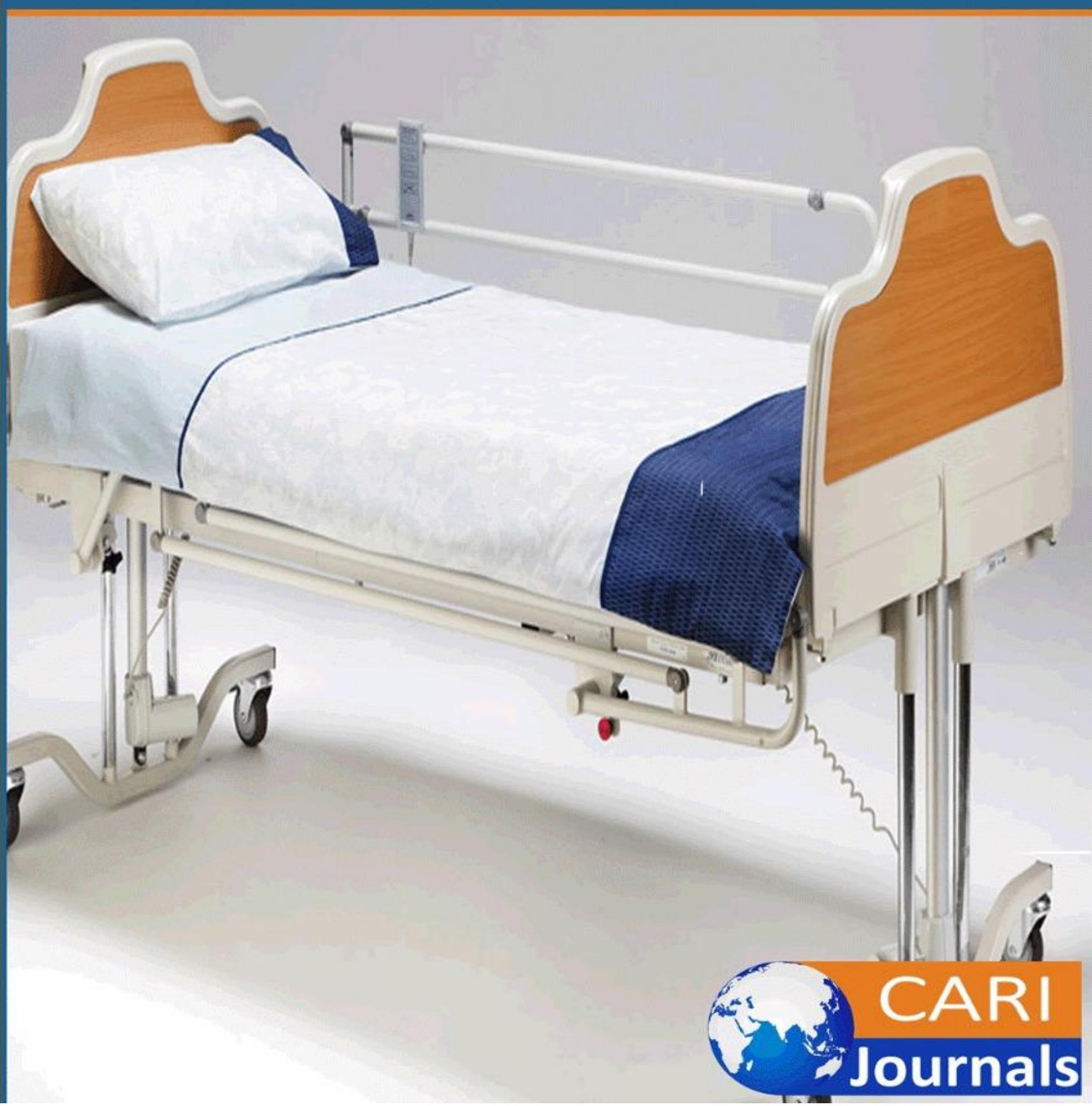


International Journal of Health, Medicine and Nursing Practice

ISSN 2710-1150 (Online)

Vol. 3, Issue No. 2, pp 48-60, 2021

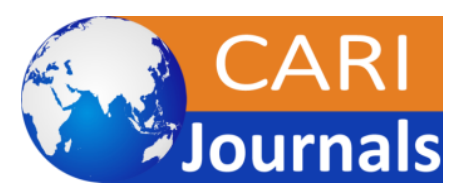

www.carijournals.org

\title{
Perception of Competence in Newly Graduated Nurses' and Possible Predictors Influencing their Perception
}

\author{
Aneela Khurram ${ }^{1}$, \\ ${ }^{1}$ Bscn student, department of LSN, The Universty of Lahore, \\ Kausar Pareveen ${ }^{2}$, \\ ${ }^{2}$ Associate professor, department of LSN, The Universty of Lahore, \\ Muhammad Hussain ${ }^{3}$, \\ ${ }^{3}$ Assistant professor, department of LSN, The Universty of Lahore, \\ Muhammad Afzal ${ }^{4}$, \\ ${ }^{4}$ Associate professor department of LSN, The Universty of Lahore, \\ Farhat Shaheen ${ }^{5}$
}

Post Graduate LSN Trainee, department of LSN, University of Lahore Teaching Hospital Corresponding Authors Email: amramkhurram@gmail.com

\begin{abstract}
Purpose: To assess the newly graduated nurses' own perception of competence and to identify possible predictors influencing their perceptions.

Methodology: A cross sectional descriptive study design. The setting will be the the Lahore School of Nursing, Allied Health Sciences The University of Lahore. Research took 4 months after the approval of synopsis Febrary 2021 to May 2021. One hundard and fifty nursing students of both gender male and female were included in this study.Using SPSS, data analysis was performed. Graphs and tables provided the details.

Result: Total 150 participants are involved this study32.0\% participants belong to 20-25 years of age group, $19.3 \%$ participants have 26-30 years of age group, $15.3 \%$ participants have $31-35$ years of age group, $12.7 \%$ participants have $36-40$ years of age and $20.7 \%$ participants have Above 41 year's age. $58.0 \%$ participants were male and $42.0 \%$ female. $28.7 \%(\mathrm{n}=43)$ participants were $1 \mathrm{st}$ year students, $26.7 \%(n=40)$ participants were 2 nd year students, $26.0 \%(n=39)$ participants were 3 th year and $18.7(n=28)$ participants were 4 th year students.

Unique contribution to theory, practice and policy: The newly graduated nurses thought they were the best at assisting patients with coping and delivering ethical, individualized nursing treatment. They thought themselves were the least qualified to evaluate results and contribute to the advancement of nursing care. The newly trained nurses thought they were competent as nurses in particular.
\end{abstract}

Key word: Graduated, Perception, Competency, Peridictors, Influecing. 


\section{Background}

\section{INTRODUCTION}

Newly trained nurses, like all graduates, come into contact with people in a variety of situations that necessitate a variety of skills. Nurse competence is described, quality of complete their work by desired consequence through a variety of real-world conditions. So practice of nurses is necessory fot the implementation to a diverse set of practices, beliefs, as well as behaviour. To achieve expertise as an expert nurse, nurses must gain real-world experience, and newly trained nurses are still learning how to do so. Nurse competence develops over time as a continuum from beginner to expert. according to modal of Dreyfus, which consists 5 phase of practice getting ranging of guided rule "knowledgeable about the practice "know how." (Donnelly and Education 2017).

There are three key approaches to the definition of clinical competence are defined from a holistic perspective. There are 1) 20 role and ability awareness, 2) a broad emphasis on problem-solving and critical thinking, and 3) a holistic approach that integrates knowledge, abilities, behaviors, beliefs, and judgement into success. Professional competence refers to a desired result under different clinical background conditions in the real world, in addition to the holistic approach used in this thesis. The importance of clinical competence being context-dependent has been emphasized, as it can be conceptualized in a variety of ways in different situations. Finally, the definition of professional competence is discussed. (Kajander-Unkuri 2016).

The primary aim of healthcare is to have the highest possible standard of treatment and patient safety (International Council of Nurses (ICN, 2019), and the World Health Organization has set equal access to healthcare as a major goal. However, due to an increase in the number of patients with complex disorders and multiple co-morbidities, as well as shorter hospital stays, healthcare in acute care hospital settings is experiencing significant changes. As a result of these factors, complicated nursing care is under more strain (Aiken, Sloane et al. 2017).

The National Board of Health and Welfare (National Board of Health and Welfare, 2016). Furthermore, persistent and long-term shortages of registered nurses (RNs) pose a major problem for healthcare in the United States and around the world. The professional integrity of RNs is critical in ensuring that high-quality nursing care is delivered and that patient safety is maximized. (WHO, 2019). Since RNs are always on the front lines of healthcare, their role is critical. Trained, competent RNs are correlated with better patient outcomes and lower mortality rates (ICN, 2019). As a result, qualified, competent RNs must be available to meet changing population needs (Smeds Alenius 2018). However, as healthcare becomes more complex and nursing shortages worsen, there is a high demand for newly trained registered nurses (NGRNs) with well-developed professional competence and job mechanisms that encourage lifelong learning to ensure quality of care and patient safety. (Organization 2017).

In the healthcare context in which nursing care is provided has changed dramatically. The government is in charge of defining the first level's principles and rules, while county administrative boards are in charge of coordinating health and medical care at the second level, Local municipalities are in charge of organizing elderly treatment and the care of individuals with physical or mental disabilities at the third level. (Source: World Health Organization, Copenhagen, 2016). Intensive treatment this complex healthcare system includes hospital settings, which are described 
as hospital wards that provide specialized or general short-term care and treatment. Intensive treatment Hospital settings, which are described as hospital wards that provide specialized or general short-term care and treatment, such as medical and surgical units, but exclude intensive care/critical care and emergency rooms, are a part of this complex healthcare system. A variety of factors, including the ever-increasing number of patients admitted with acute diseases or chronic and complex co-morbidities, have resulted in changes to acute care hospital settings in recent years (Charette, McKenna et al. 2020).

In addition, the number of elderly frail patients with multiple chronic diseases is on the rise. Furthermore, patients who may have previously been admitted to intensive care units are now more often treated on medical or surgical wards in hospitals. Furthermore, nosocomial infections such as pneumonia and post-operative infections are on the rise. The ongoing evolution of new medical advances, procedures, and technology are other factors contributing to the increased complexity of cases in acute care hospital settings (Zieber and Sedgewick 2018).

Newly trained nurses, like all graduates, come into contact with people in a variety of situations that necessitate a variety of skills. Nurse competence is described as the ability to complete a task with a desired outcome under a variety of real-world conditions. This means that nursing practice necessitates the implementation of a diverse set of skills, beliefs, and attitudes. To achieve expertise as an expert nurse, nurses must gain real-world experience, and newly trained nurses are still learning how to do so. Nurse competence develops over time as a continuum from beginner to expert, according to Dreyfus and Dreyfus' model, which consists of five stages of skill acquisition ranging from rule-guided "knowing that" to experienced-based "know how." (Donnelly and Education 2017).

There are three key approaches to the definition of clinical competence are defined from a holistic perspective. There are 1) 20 role and ability awareness, 2) a broad emphasis on problem-solving and critical thinking, and 3) a holistic approach that integrates knowledge, abilities, behaviors, beliefs, and judgement into success. Professional competence refers to a desired result under different clinical background conditions in the real world, in addition to the holistic approach used in this thesis. The importance of clinical competence being context-dependent has been emphasized, as it can be conceptualized in a variety of ways in different situations. Finally, the definition of professional competence is discussed. (Kajander-Unkuri 2016).

The primary aim of healthcare is to have the highest possible standard of treatment and patient safety (International Council of Nurses (ICN, 2019), and the World Health Organization has set equal access to healthcare as a major goal. However, due to an increase in the number of patients with complex disorders and multiple co-morbidities, as well as shorter hospital stays, healthcare in acute care hospital settings is experiencing significant changes. As a result of these factors, complicated nursing care is under more strain (Aiken, Sloane et al. 2017).

The National Board of Health and Welfare (National Board of Health and Welfare, 2016). Furthermore, persistent and long-term shortages of registered nurses (RNs) pose a major problem for healthcare in the United States and around the world. The professional integrity of RNs is critical in ensuring that high-quality nursing care is delivered and that patient safety is maximized. (WHO, 2019). Since RNs are always on the front lines of healthcare, their role is critical. Trained, competent RNs are correlated with better patient outcomes and lower mortality rates (ICN, 2019). As a result, 
qualified, competent RNs must be available to meet changing population needs (Smeds Alenius 2018). However, as healthcare becomes more complex and nursing shortages worsen, there is a high demand for newly trained registered nurses (NGRNs) with well-developed professional competence and job mechanisms that encourage lifelong learning to ensure degree of patient safety and care (Organization 2017).

In the healthcare context in which nursing care is provided has changed dramatically. The government is in charge of defining the first level's principles and rules, while county administrative boards are in charge of coordinating wellbeing or care of medical at second level, Local administrative district were in charge of organizing elderly treatment and the care of individuals with physical or mental disabilities at the third level. (Source: World Health Organization, Copenhagen, 2016). Intensive treatment this complex healthcare system includes hospital settings, which are described as hospital wards that provide specialized or general short-term care and treatment. Intensive treatment Hospital settings, which are described as hospital wards that provide specialized or general short-term care and treatment, such as medical and surgical units, but exclude intensive care/critical care and emergency rooms, are a part of this complex healthcare system. A variety of factors, including the ever-increasing number of patients admitted with acute diseases or chronic and complex co-morbidities, have resulted in changes to acute care hospital settings in recent years (Charette, McKenna et al. 2020).

In addition, the number of elderly frail patients with multiple chronic diseases is on the rise. Furthermore, patients who may have previously been admitted to intensive care units are now more often treated on medical or surgical wards in hospitals. Furthermore, nosocomial infections such as pneumonia and post-operative infections are on the rise. The ongoing evolution of new medical advances, procedures, and technology are other factors contributing to the increased complexity of cases in acute care hospital settings (Zieber and Sedgewick 2018).

\section{Literature Review}

Meretoja et al. created the NCS, which contain about seventy three of 73 parts grouped into 7 abilittie category, each six among nine parts of class: Serving, position, education-work, designation purpose, handling circumstances, therapeutic interventions, ensuring consistency, and finally, ensuring safety, function in the workplace Competency connected to assisting the patients in coping or delivering right personalized treatment make up the helping job. Distinguishing informative necessarily of patient as well as family of patient, expanding care of them selves options, or care to collegue are all part of the teaching-coaching category. Diagnostic functions are concerned with defining and assessing the patient's unique condition, while management functions are concerned with understanding changing circumstances, prioritizing tasks in a flexible and effective manner, and encouraging patient cooperation. Therapeutic interventions include items such as coordinating and making decisions about patient treatment based on clinical conditions, as well as consulting with other team members. Quality assurance entails assessing outcomes and leading to the advancement of patient treatment. Finally, the job role group is concerned with behaving collaboratively, responsibly, and independently, as well as with maintaining professional growth (Meretoja, Isoaho et al. 2018).

The disparity anong a graduated and student nurse is reported to be a large part of the difference, and newly qualified nurse were reportable to be unprepared about that responcipilities. He described 
ability of "Quality of carry out work and function, expectable standardized," they too be noted problem of variance to necessitate among services. About, ninty percent scholarly leader thought fresh skilled nursing staff were equipped for providing effective care to patient, while only ten percent manager of health care thought so. Nurse Managers, on the other hand, thought the nurses were more competent than the nurses themselves. (Wangensteen, Johansson et al. 2018).

Nurses that have recently graduated enter clinical practise, which has changed dramatically in the last 20 years. Furthermore, the number of usable beds in nursing homes has declined by $20 \%, 20$ year before resulting in a rise in the number of patients requiring home treatment. Nurses' expertise is being put to the test as specialis in any field of medicine and community become more prevalent. So inquire about nurses who have newly graduate perceptions of their competencies in environments well-marked with high efficacy, strict time constraints, and demands to patient, their family, colleague, wellbeing consultant. Thats research examines recently graduate nursing staff view their competence and the factors that can influence their performance in various settings. The purpose were discover recently gradual nursing staff' conceptuality of competencies and determine doable predictor's consequence their perception

(Helles $\varnothing$ and Fagermoen 2017).

Competence, according to Ellström, is intertwined with the principles of integrity, competency, and ability. The distinction between competency and competence in nursing is unclear, and these terms have been used interchangeably in research literature. In most research, however, competency refers to the skills themselves, while competence refers to the ability to perform (Ellström 2017).

According to Bvumbwe \& Mtshali, an objective concept of competence can be seen in the skill or capacity of a performer. Competence is linked to all aspects of nursing care and is regarded as a critical factor. In the healthcare system, it is at the heart of nursing education programmes and nursing care. Several components must be defined in order to comprehend nursing competence. The nursing method, for starters, is at the heart of nursing care; it is adaptable to any patient, environment, or variable, and it entails assessing, diagnosing, preparing, implementing, and evaluating. Second, clinical analytical skills such as problem solving and logical thinking are used in nursing processes.

\section{The study objective will be:}

To assess the newly graduated nurses' own perception of competence and to identify possible predictors influencing their perceptions.

\section{OPERATIONAL DEFINITIONS}

PERCEPTION : In this study, perception the way in which something is regarded, understood, or interpreted it will be measured through a 16-item multiple-choice question adopted from the Knowledge Questionnaire (Mileder, Gressl et al. 2019).

\section{HYPOTHESIS}

\section{Null Hypothesis Ho:}

There is no effect of newly graduated nurses' own perception of competence and possible predictors influencing their perceptions

\section{Alternative Hypothesis $\mathrm{H}_{1}$ :}


International Journal of Health, Medicine and Nursing Practice

ISSN 2710-1150 (Online)

Vol. 3, Issue No. 2, pp 48-60, 2021

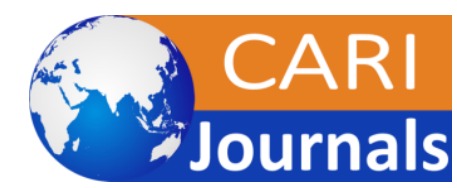

www.carijournals.org

There is an effect of newly graduated nurses' own perception of competence and possible predictors influencing their perceptions

\section{MATERIALS AND METHODS}

Study Designs: A cross sectional study

Setting: The setting will be the Lahore school of nursing the university of Lahore

Duration of Study: 4 months after the approval of synopsis

Sample Size: sample size calculated from base article. Which is 150 .

The sample size of the study was 150 nurses significant level 0.05

$\mathrm{N}=240$

Sample size determined by the formula of Slovin

$\mathrm{n}=\mathrm{N} / 1+\mathrm{N}(\mathrm{e})^{2}$

$\mathrm{n}=240 / 1+240(0.05)^{2}$

$\mathrm{n}=240 / 1+240(0.0025)$

$\mathrm{n}=240 / 1+0.6$

$\mathrm{n}=240 / 1.6$

$\mathrm{n}=150$

Sampling Technique: Simple random sampling

Sample Selection: selected hospital Lahore

Inclusion Criteria: All nursing student will be included in this study

Willingness to participate: Only Willing participant

Exclusion Criteria: The participant will be excluded in this study who:

- $\quad$ Student nurses who already took training

- $\quad$ Have already received any educational training on this topic.

\section{ETHICAL CONSIDERATIONS}

- $\quad$ All of these participants will have written informed consent (attached).

- $\quad$ All documents and data gathered would be kept private.

- $\quad$ During the study, participants will remain anonymous.

- $\quad$ The participants will be advised that the research protocol has no drawbacks or hazards.

- $\quad$ The study's theoretical advantage to participants would be an improvement in recently graduating nurses' own expectations of expertise and possible determinants affecting those views.

- - We will do everything possible to protect participants' privacy. Any publication arising from this research would not disclose the participant's name.

$\bullet \quad \bullet$

- Convince the respondents that they have the right to revoke their consent at any moment. If they want not to participate or withdraw from the sample, they will not be penalized in any way.

DATA COLLECTION PROCEDURE

\section{Recruitment:}


International Journal of Health, Medicine and Nursing Practice

ISSN 2710-1150 (Online)

Vol. 3, Issue No. 2, pp 48-60, 2021

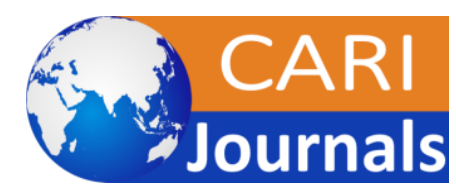

$\underline{\text { www.carijournals.org }}$

The study participants will be recruited through the process of simple random sampling. A meeting will be arranged with all the eligible participants. In which the researcher will personally explain the study purpose, procedure, and benefits to the participant. In the meeting, participant's questions regarding the study will clear. Demographic data will be collected through face to face intervention and the knowledge of client will be assessed through instrument, Assessment including questionnaires, observation, focus groups, and interviews.

\section{Study Variables:}

Perception will be measured through 23-item multiple-choice questions adopted from perception Questionnaire.

\section{Methods for Collection of Data:}

Facilitator evaluators will be trained regarding the scoring of each scale data collection. The data will be collected after the approval of the synopsis at the given setting.

\section{ANALYSIS PROCEDURE}

The data analysis will be made using the Statistical Package for the Social Sciences (SPSS) version 25 software to predict the differences in the outcome variables. For qualitative variables, frequencies and percentages will be measured, while mean and standard deviation will be calculated for quantitative variables. Significance different will be measured on $\mathrm{P}$ value $<0.05$.

\section{RESULT}

Table 1: Demographic characteristic of the participants

\begin{tabular}{|l|l|l|}
\hline Sr\# & Demographic Characteristics & Response $\boldsymbol{f}(\%)$ \\
\hline 1 & Age & \\
\hline & $20-25$ years & $48(32.0 \%)$ \\
\hline & 26-30 years & $29(19.3 \%)$ \\
\hline & $31-35$ years & $23(15.3 \%)$ \\
\hline & $36-40$ years & $19(12.7 \%)$ \\
\hline & Above 41 years & $31(20.7 \%)$ \\
\hline & Total & $150(100 \%)$ \\
\hline 2 & Sex & \\
\hline & Male & $87(58.0 \%)$ \\
\hline & Female & $63(42.0 \%)$ \\
\hline & Total & $150(100 \%)$ \\
\hline 3 & Year of study & \\
\hline & $1^{\text {st } y e a r ~}$ & $43(28.7 \%)$ \\
\hline & $2^{\text {nd }}$ year & $40(26.7 \%)$ \\
\hline & $3^{\text {th }}$ year & $39(26.0 \%)$ \\
\hline & $4^{\text {th }}$ year & $28(18.7 \%)$ \\
\hline & Total & $150(100 \%)$ \\
& & \\
\hline
\end{tabular}


This section represents the distribution of participant by demographic characteristics. The data is summarized in terms of frequency and percentage. Table \# 01 show that $32.0 \%$ participants belong to 20-25 years of age group, $19.3 \%$ participants have $26-30$ years of age group, $15.3 \%$ participants have 31-35 years of age group, $12.7 \%$ participants have $36-40$ years of age and $20.7 \%$ participants have Above 41 year's age. 58.0\% participants were male and $42.0 \%$ female. $28.7 \% \quad(n=43)$ participants were 1 st year students, $26.7 \%(n=40)$ participants were 2 nd year students, $26.0 \%(n=39)$ participants were 3 th year and $18.7(n=28)$ participants were 4 th year students.

Table 2: Table \#02 Newly Graduated Nurses' Most Frequently Used Competence

\begin{tabular}{|l|l|l|l|l|l|}
\hline $\begin{array}{l}\text { Sr. } \\
\text { NO }\end{array}$ & Items & $\begin{array}{l}\text { Very Often } \\
\text { used } \\
\mathbf{f ( \% )}\end{array}$ & $\begin{array}{l}\text { Not applicable } \\
\text { in my work } \\
\mathbf{f ( \% )}\end{array}$ & $\begin{array}{l}\text { Competence } \\
\text { Category }\end{array}$ & Total \\
\hline $\mathbf{1 .}$ & $\begin{array}{l}\text { Patient treatment is planned } \\
\text { based on the individual's needs. }\end{array}$ & $82(54.7 \%)$ & $68(45.3 \%)$ & Helping Role & $150(100 \%)$ \\
\hline $\mathbf{2 .}$ & Acting autonomously & $80(53.3 \%)$ & $70(46.7 \%)$ & Work role & $150(100 \%)$ \\
\hline $\mathbf{3 .}$ & $\begin{array}{l}\text { Supporting patient's coping } \\
\text { strategies }\end{array}$ & $91(60.7 \%)$ & $59(39.3 \%)$ & Helping Role & $150(100 \%)$ \\
\hline $\mathbf{4 .}$ & $\begin{array}{l}\text { Making decision concerning } \\
\text { patient care taking the particular } \\
\text { situation into account }\end{array}$ & $59(39.3 \%)$ & $91(60.7 \%)$ & $\begin{array}{l}\text { Therapeutic } \\
\text { intervention }\end{array}$ & $150(100 \%)$ \\
\hline $\mathbf{5 .}$ & $\begin{array}{l}\text { Planning care consistently with } \\
\text { resources available }\end{array}$ & $63(42.0 \%)$ & $87(58.0 \%)$ & $\begin{array}{l}\text { Managing } \\
\text { situations }\end{array}$ & $150(100 \%)$ \\
\hline $\mathbf{6 .}$ & $\begin{array}{l}\text { Ethical principles drive } \\
\text { decision-making. }\end{array}$ & $79(52.7 \%)$ & $71(47.3 \%)$ & Helping Role & $150(100 \%)$ \\
\hline $\mathbf{7 .}$ & $\begin{array}{l}\text { Taking active steps to maintain } \\
\text { and improve my professional } \\
\text { skills }\end{array}$ & $68(45.3 \%)$ & $82(54.7 \%)$ & $\begin{array}{l}\text { Teaching } \\
\text { coaching }\end{array}$ & $150(100 \%)$ \\
\hline $\mathbf{8 .}$ & $\begin{array}{l}\text { Examining the health of patients } \\
\text { from a variety of angles }\end{array}$ & $57(38.0 \%)$ & $93(62.0 \%)$ & $\begin{array}{l}\text { Diagnostic } \\
\text { function }\end{array}$ & $150(100 \%)$ \\
\hline $\mathbf{9 .}$ & $\begin{array}{l}\text { Prioritizing my tasks in a } \\
\text { flexible manner in response to } \\
\text { changing circumstances }\end{array}$ & $90(60.0 \%)$ & $60(40.0 \%)$ & $\begin{array}{l}\text { Managing } \\
\text { situations }\end{array}$ & $150(100 \%)$ \\
\hline $\mathbf{1 0 .}$ & $\begin{array}{l}\text { able to recognize when a patient } \\
\text { needs social assistance }\end{array}$ & $66(44.0 \%)$ & $84(56.0 \%)$ & $\begin{array}{l}\text { Diagnostic } \\
\text { function }\end{array}$ & $150(100 \%)$ \\
\hline
\end{tabular}

Table \# 02 show that $54.7 \%$ participants were very often used of planning patient care according to individual needs and $45.3 \%$ participants were not applicable in my work. 53.3\% participants were very often used of acting autonomously and $46.7 \%$ participants were not applicable in my work. $60.7 \%$ participants were very often used Supporting patient's coping strategies and 39.3\% participants were not applicable in my work. 39.3\% participants were very often used making decision regarding patient care captivating the specific state into account and $60.7 \%$ participants were not applicable in my work. 52.7\% participants were very often used of Decision making guided by ethical values and $47.3 \%$ participants were not applicable in my work. $45.3 \%$ Participants were often reminded of the importance of taking proactive action to preserve and develop my technical abilities. and 54.7 participant were not applicable in my work. 60.0\% Participants became often used to prioritizing my tasks in a flexible manner in response to changing circumstances. $40.0 \%$ 
participants were not applicable in my work. $44.0 \%$ of participants were able to recognize patients' need for social assistance on a regular basis. $65.0 \%$ participants were not applicable in my work

Table 3: Newly Graduated Nurses' Least Used Competence

\begin{tabular}{|c|c|c|c|c|c|}
\hline $\begin{array}{l}\text { Sr. } \\
\text { NO }\end{array}$ & Items & $\begin{array}{l}\text { Very } \\
\text { Often used } \\
f(\%)\end{array}$ & $\begin{array}{l}\text { Not } \\
\text { applicable } \\
\text { in my } \\
\text { work } f(\%)\end{array}$ & $\begin{array}{l}\text { Competence } \\
\text { Category }\end{array}$ & Total \\
\hline 1. & $\begin{array}{l}\text { In the unit, coordinating student nurse } \\
\text { mentoring }\end{array}$ & $73(48.7 \%)$ & $77(51.3 \%)$ & Work role & $150(100 \%$ \\
\hline 2. & $\begin{array}{l}\text { Mentoring novices and advanced } \\
\text { beginners }\end{array}$ & $88(58.7 \%)$ & $62(41.3 \%)$ & Work role & $150(100 \%$ \\
\hline 3. & $\begin{array}{l}\text { In my unit, I'm creating orientation } \\
\text { plans for new nurses. }\end{array}$ & $85(56.7 \%)$ & $65(43.3 \%)$ & $\begin{array}{l}\text { Teaching } \\
\text { coaching }\end{array}$ & $150(100 \%$ \\
\hline 4. & $\begin{array}{l}\text { Some members of the team are being } \\
\text { shown how to observe patients. }\end{array}$ & $88(58.7 \%)$ & $62(41.3 \%)$ & $\begin{array}{l}\text { Diagnostic } \\
\text { function }\end{array}$ & $150(100 \%$ \\
\hline 5. & $\begin{array}{l}\text { When necessary, organizing briefing } \\
\text { sessions for the care team }\end{array}$ & $63(42.0 \%)$ & $87(58.0 \%)$ & $\begin{array}{l}\text { Managing } \\
\text { situations }\end{array}$ & $150(100 \%$ \\
\hline 6. & $\begin{array}{l}\text { Mentoring takes into account the } \\
\text { skill development of students nurses. }\end{array}$ & $83(55.3 \%)$ & $67(44.7 \%)$ & $\begin{array}{l}\text { Teaching } \\
\text { coaching }\end{array}$ & $150(100 \%$ \\
\hline 7. & Updating written guidelines for care & $89(59.3 \%)$ & $61(40.7 \%)$ & $\begin{array}{l}\text { Therapeutic } \\
\text { interventions }\end{array}$ & $150(100 \%$ \\
\hline 8. & $\begin{array}{l}\text { Making a contribution to the } \\
\text { continued growth of multidisciplinary } \\
\text { nursing teams }\end{array}$ & $95(63.3 \%)$ & $55(36.7 \%)$ & $\begin{array}{l}\text { Therapeutic } \\
\text { interventions }\end{array}$ & $150(100 \%$ \\
\hline 9. & Providing advice to the medical staff & $81(54.0 \%)$ & $69(46.0 \%)$ & $\begin{array}{l}\text { Therapeutic } \\
\text { interventions }\end{array}$ & $150(100 \%$ \\
\hline 10. & Therapeutic interventions & $83(55.3 \%)$ & $67(44.7 \%)$ & $\begin{array}{l}\text { Teaching } \\
\text { coaching }\end{array}$ & $150(100 \%$ \\
\hline
\end{tabular}

Table \# 03 show that $48.7 \%$ participants were very often coordinating student nurse mentoring in the unit and 51.3\% participants were not applicable in my work. 58.7\% participants were very often Mentoring novices and advanced beginners $41.3 \%$ participants were not applicable in my work. $56.7 \%$ participants were very often used of developed location program for new nurses in my unit and $43.3 \%$ were not applicable in my work. $42.0 \%$ participants were very often of where required, organizing briefing sessions for the care team $58.0 \%$ participants were not applicable in my work. $55.3 \%$ participants were very often of taking students nurse's skill acquisition into account in mentoring $44.7 \%$ participants were not applicable in my work. 59.3\% participants were very often of Updating written guidelines for care $40.7 \%$ participants were not applicable in my work. $63.3 \%$ participants were very often of Contributing to further development of multidisciplinary teams nursing activities and $36.7 \%$ participants were not applicable in my work. 54.0\% participants were very often of providing consultation for the care team $46.0 \%$ participants were not applicable in my work. $55.3 \%$ participants were very often of Therapeutic interventions $44.7 \%$ participants were not applicable in my work 


\section{DISCUSSION}

In this report, newly qualified nurses rated their overall level of expertise as high. The majority of 150 nurses participated in the study were between $20-25$ years, $40(26.0 \%)$ were also mainly $2^{\text {nd }}$ year students. Mostly $54.7 \%$ participants were very often used of design patients cares rendering by client requirements. Majority of participants were not willing in the making decision in terms of health treatment, taking into account the unique circumstances and mostly participants are not applicable in preparation care reliably with incomes existing nurses used helping role competence in decision making guided by ethical values. According to Meretoja, Isoaho et al 2016 The supporting function expertise was used the most commonly by nurses, according to many surveys using the NCS. This finding suggests that newly trained nurses are introduced to circumstances in which they use the facets of the helping profession, which they seem to be well equipped for, and develop more competence in these aspects as a result. (Meretoja, Leino-Kilpi et al. 2016). In the finding of this study mostly newly graduated nurses were not used teaching coaching competency taking active steps to maintain and improve my professional skills. According to Salonen et al., 2017 In comparison to results in research involving more seasoned nurses, teaching-coaching was the skill group found to be least commonly used by our newly qualified nurses. (Salonen, Kaunonen et al. 2017). In this study newly graduated nurses were not aware diagnostic function competence to examining patient' comfort to numerous outlooks but majority of nurses are good competence in managing situation of Taking priority the efforts in a flexible manner in response to changing circumstances. The frequency of usage, according to Leino-Kilpi et al. 2018, played a significant role in the skill rating, describing between 10\% (lowest, handling situations) and 40\% (highest, supporting role) of the variability. There has also been a strong association among conscience degree of competence and intensity of using expertise, but the correlation coefficients have not been published. (Meretoja and Leino-Kilpi 2018). In this study newly graduated nurses were not working role competence coordinating student nurse mentoring in the unit in the other hand majority of nurses used good working role in the mentoring novices and advanced beginners. According to Scheffer \& Rubenfeld, This was true in 2018 for both the overall NCS ranking and the seven skill groups. These studies back up the idea that CT is an important part of clinical integrity and nursing care efficiency. (Scheffer and Rubenfeld 2018). In this study majority of newly graduated nurse's good teaching coaching in developing orientation programs for new nurses in my unit and in the other hand majority of nurses perform good diagnostic function in the coaching other staff members in patient observation skills. According to Alfaro-LeFevre, 2019 CT refers to goal-directed reasoning that focuses on making decisions based on facts rather than assumptions. While problem solving focuses on identifying and solving problems, CT goes further by posing questions and criticising approaches.(Morrison and Free 2019). In this study majority of newly graduated nurses were not show good competency in managing situation assembling updating terms for the carefulness group while desired and have good teaching coaching taking students nurse's expertise achievement into version in mentoring. Majority 89(59.3\%) of newly graduated nurses used therapeutic interventions in updating written guidelines for care, assisting in the creation of multidisciplinary teams' nursing practices and delivering treatment team consultation According to Meretoja, Isoaho, et al2017 .'s study, those employed in community health care had slightly higher scores on diagnostic roles, clinical treatments, and work job than those working in specialty health care. Surprisingly, our community health care nurses posted ratings that were comparable to seasoned nurses in these competency categories. Unfortunately, nurses serving in community health care were not involved in any of the trials using the NCS that were found and checked for this report. Our results could mean that recently trained nurses employed in community health care are exposed 
to harmful substances, and improve their skills in these areas to a larger degree than those who work in hospitals. In this study majority of newly graduated nurses used teaching coaching competency for therapeutic intervention.

\section{Conclusion}

The newly graduated nurses thought they were the best at assisting patients with coping and delivering ethical, individualized nursing treatment. They thought themselves were the least qualified to evaluate results and contribute to the advancement of nursing care. The newly trained nurses thought they were competent as nurses in particular.

\section{Strength}

In this analysis, Cluster sampling was used, and is classified as one of the random sampling techniques. This improves the study's credibility. The research included more than 150 newly trained nurses. The findings of this analysis were based on the forward approach, although other approaches were also used. The same variables tended to be important predictors regardless of which method was used. There are several approaches to pick from when it comes to regression analysis. When following the forward strategy, the computer first searches for the predictor that best predicts the outcome variable, and moves on to the next variables that best predict the outcome variable have a major impact on the outcome variable's prediction.

\section{Limitation}

This might be argued that self-assessments are unimportant, and different views on nurses' competence have been noted. Different tests of competence have been recorded by supervisors and practicing nurses on several occasionsIn the other hand, nurses' success was ranked better than the nurses' own. It will be addressed the importance of explaining newly qualified nurses' own views of competence. Employers, bosses, nursing peers, and other health care professionals all have different perspectives on young nurses' expertise.

\section{Acknowledgement}

Thankful all students who participats in this study. I also thankful to university administration.

\section{Reference}

Aiken, L. H., et al. (2017). "Nursing skill mix

in European hospitals: cross-sectional study

of the association with mortality, patient ratings, and quality of care." 26(7): 559568.

Bvumbwe, T. M. and N. G. J. C. Mtshali (2018). "A middle-range model for improving quality of nursing education in Malawi." 41(1): 1-11.

Charette, M., et al. (2020). "Measurement properties of scales assessing new graduate nurses' clinical competence: A systematic review of psychometric $\quad$ properties." $\quad 110$ : 103734. 
International Journal of Health, Medicine and Nursing Practice

ISSN 2710-1150 (Online)

Vol. 3, Issue No. 2, pp 48-60, 2021

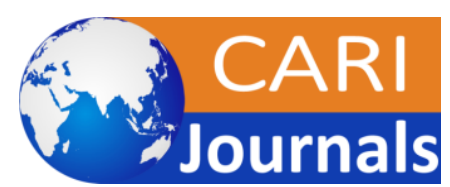

Donnelly, J. F. J. T. and T. Education (2017). "Schooling Heidegger: On being in teaching." 15(8): 933-949.

Ellström, P.-E. (2017).Kompetens, utbildning och lärande i arbetslivet: problem, begrepp och teoretiska perspektiv, Publica.

Hellesø, R. and M. S. J. I. j. o. i. c. Fagermoen (2017). "Cultural diversity between hospital and community nurses: implications for continuity of care." $\mathbf{1 0 .}$

Kajander-Unkuri, S. (2016). "Nurse competence of graduating nursing students."

Meretoja, R., et al. (2018). "Nurse competence scale: development and psychometric testing." 47(2): 124- 133.

Meretoja, R. and H. J. J. T. J. o. N. A. Leino- Kilpi $\quad$ (2018). "Instruments for evaluating nurse competence." 31(7/8): 346-352.

Meretoja, R., et al. (2016). "Comparison of nurse competence in different hospital work environments." 12(5): 329- 336.

Mileder, L. P., et al. (2019). "Paramedics' Newborn Life Support Knowledge and Skills Before and After a Targeted Simulation-Based Educational Intervention." Frontiers in pediatrics 7: 132 .

Morrison, S. and K. W. J. J. o. N. E. Free (2019). "Writing multiple-choice test items that promote and measure critical thinking." 40(1): 17-24.

Organization, W. H. (2017). "Building resilience: a key pillar of Health 2020 and the Sustainable Development Goals: examples from the WHO Small Countries Initiative."

Salonen, A. H., et al. (2017). "Competence profiles of recently registered nurses working in intensive and emergency settings." 15(8): 792-800.

Scheffer, B. K. and M. G. Rubenfeld (2018). A consensus statement on critical thinking in nursing, SLACK Incorporated Thorofare, NJ. 
International Journal of Health, Medicine and Nursing Practice ISSN 2710-1150 (Online)

Vol. 3, Issue No. 2, pp 48-60, 2021

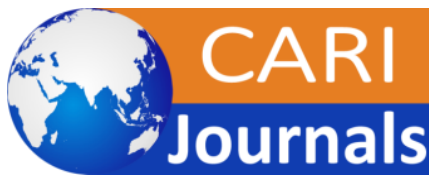

Wangensteen, S., et al. (2018). "The first year as a graduate nurse-an experience of growth and development." 17(14): 1877-1885.

Wangensteen, S., Johansson, I. S., ～Björkström, M. E., \& Nordström, G. (2016). ～Newly graduated nurses' perception of competence and possible predictors: a cross-sectional survey. Journal of Professional Nursing, 28(3), 170-181.

Zieber, M. and M. J. N. e. t. Sedgewick (2018). "Competence, confidence and knowledge retention in undergraduate nursing students - a mixed method study." 62: 16-21. 